\title{
The Manners Of Cognitive Processin Translating English Phrasal Verbs Into Indonesian
}

\author{
Fitri Ervina Tarigan', Anni Holila Pulungan', Rahmad Husein ${ }^{3}$
}

1,2,3 State University of Medan, Indonesia

Corresponding Author: @fitriervinatarigan@gmail.com

This study dealt with the cognitive process of students in translating
English Phrasal Verbs into Indonesian by using the think-aloud protocol
(TAP) technique and introspective interview. The objectives of the study
was1) to elaboratethe manner of cognitive processes occurring in
translating English Phrasal Verbs into Indonesian. This research was
conducted by descriptive qualitative design. The source of data was the
bilingual students, they were sixth semester students of English Education
Program at State University of Medan. The source of data were taken by
using Snowballing Technique. The data consisted of the transcription of
audio recorded observation of think-aloud protocols (TAP), and the
transcription of interview. The findings showed that there are six
behaviors available during the process of translation done by the students,
namely 1) reading the text, 2) alternating between the SL and the TL 3)
monitoring the proposed translation, 4) consulting the dictionary 5)
paraphrasing, and 6) translation. The cognitive processes occur when the
subjects 1) read the text, either they read the whole SL or segment by
segment, 2) kept repeating the term (the lexical) which indicates
hesitation, questioning, and remembering the real meaning 3) were not
able to make decision for an equivalent, 4) did not understand the
meaning of verbs and consult the dictionary, 6) tried to clarify a concept
and reformulate a proposed translation by paraphrase, and 7) wrote down
a translation and express it orally.

\section{INTRODUCTION}

The term translation has several meanings. It can refer to product (the text has been translated) or the process (the act of producing the translation, known as translating). The process of translation between two different written languages involves the translator change the original written text ( source ext or ST) in a different verbal language (target text or TT) .

Translation defined as the rephrasing of a communication expressed (message) in one language, the source language (SL), into another language, the target language (TL). Three notions are involved: SL, message and TL. The translator, therefore, should master the linguistic and non-linguistic knowledge 
Ability : Journal of Education and Social Analysis

Volume 2, Issue 4, Oktober 2021

Page : 102-109

of both SL and TL. Linguistically, s/he should master the word (lexicon), phrasal expression, structure of the sentence, syntactic relation between the various elements of the sentence, and semantic relation of SL and TL. Nonlinguistic knowledge refers to the previous knowledge of the translator possesses towards the text, whether s/he has known and read it before.

In rephrasing SL into TL, the translator should not translate SL based on the SL language structure. It should be based on TL language structure so that the final message will be acceptable in the communication process. It is feasible to make adjustment such as shifts to make the translation acceptable, equivalent and natural. As Nida (1982:12) explains that the best translation does not sound like a translation.

During the activity of rephrasing SL into TL, the process of translation takes place. Such translation is known as translation process (Kiraly, 1995:18). Empirically, translation process aims to investigate what goes on in the mind of person while he or she is translating. Psycholinguistically, it sets out to establish how the translator processes information in bilingual communication. In association with the translation process, the researcher have turned to the cognitive science and adopted think-aloud protocol (TAP) from experimental psychology (Danks, 1997:7).

The process of translation between two different written languages involves the transferring an original written text (the source text or ST) in the original verbal language (the source language or SL) into a written text (the target text or TT) in a different verbal language (the target language or TL) by the translator (Munday, 2001:5). As its simplest, the process of translation involves the transferring of meaning from a text in one language into a text in another.

It is also happened while translating English phrasal verbs into its Indonesian Context. Since English phrasal verbs has several meaning based on its context, somehow the translator feel difficult to translate it naturally, and bring to target text context. Deals with those facts the cognitive process or mental process plays important role in this part to get into the real meaning of it. As the observation data shown below:

SL : Three masked gun men hold up the Security Bank this afternoon

$T L_{1}$ : Tiga lelaki bertopeng menyerang pengaman bank siang ini.

TL2: Tiga lelaki bertopeng menikam pengaman bank Siang Ini

TL3: Tiga lelaki bertopeng menggrebek pengaman bank sore ini.

So, from the data above actually based on its context hold up in bahasa Indonesia means menyerang, but different translator has a different style of the way the word process in his mind, the processes were activated were different 
Ability : Journal of Education and Social Analysis

Volume 2, Issue 4, Oktober 2021

Page : 102-109

with the theory possesses by Bell so, the meaning in the translator's mind is different with the meaning intended in target language, because they just translated it literally and pragmatically separated with the context, they translated it just by correlated it with what they have known before as the meaning of the phrasal verbs

This transferring constitutes mental processes which rely on sophisticated information processing skills. The mental processes are understood by investigating the cognitive activities in a translator's mind during the performance of translating. In investigating the mental processes, the translator is asked to verbalize something about his/her cognitive activities during the performance of translation tasks using the think-aloud protocol (TAP) technique through observation and to do in retrospect what they have done through interview . According to Seleskovitch and Lederer (Munday, 2001:80), there is three-stage process of translation: reading and understanding, deverbalization, and re-expression. In reading and understanding, the translator uses his/her linguistic competence and 'world knowledge' to grasp the sense of the source text. The linguistic component needs to be understood by reference not only to explicit but also to implicit meaning in an attempt to recover the authorial intention. The world knowledge is de-verbalized, theoretical, general, encyclopaedic and cultural, and activated differently by different translators and in different texts. The verbalization is an essential intermediate phase if the translator is to avoid transcoding and calques. Transcoding is the replacement of SL linguistic structures of various types (words, phrases, clauses) by corresponding TL. Calque is a special kind of borrowing where the SL expression or structure is transferred in a literal translation. Re-expression takes place where the target text is constituted and given form based on the deverbalized understanding of sense. A fourth stage, verification, where the translator revisits and evaluates the target text, is added by Delisle (Lederer, 2003:38)

In reality, Dancette (1997:85) finds out that, when the translators face with a difficulty, they can recall their questions, hypotheses, and some of the steps of their reasoning. Therefore, they are able to talk about the process. However, processes are not visible, only clues to such processes are visible. These processes are able to observe through the observation of the translators' behaviours. Behaviours are an indication of a process which helps the observer to make reasonable hypotheses on what process is involved and validate intuitions about the nature of processes.

The theories proposed by Bell (2001), Seleskovitch and Lederer (2001) and Dancette (1997) which involve mental process in translation process, from the 
translator's perspective and looking toward the mental processes going on in the individual translator's mind during the process of translation, lead the writer's interest to conduct this scientific study. The writer tried to verify whether the theories are applicable to the English students at English Applied Linguistic or there is any difference. This study analyzed the cognitive process of students in translating English Phrasal Verb by using Think-Aloud Protocol (TAP) and retrospective interview. English Phrasal Verbs are choosen as a source languange because as a translators, they need to broadenes their understanding about the using of English Phrasal Verbs, the meaning based on its context. Because all in all the researcher found that in translating text or sentence which consist of English Phrasal Verb such a common the translators are confused and get in to the wrong meaning and did not suitable with the context.

\section{RESEARCH METHOD}

This research was a qualitative research since the data were ordinarily expressed in qualitative terms.The data of this research werephrases which were consist of English Phrasal Verbs.to objectively describe and explain the phenomena on the cognitive process of students in translating English Phrasal Verb by using think-aloud-protocol (TAP).

Since this study was tightly pertinent to the investigation of the cognitive process of the students in translating English Phrasal Verb into Bahasa Indonesia, the requirement in determining the source of data this study is bilingual students, i.e, sixth-semester of English Education department of Art and Literature Department, Medan State University.

\section{RESULT AND DISCUSSION}

\section{Subject Manners}

$\mathrm{AH} \quad-$ Reading the sentences

- Alternanting between SL to TL

- Paraphrasing

- Translation

AMH - Reading the Sentences

- Consulting the dictionary

- Translation

DL - Reading the sentence

- Alternating between SL to TL

- Parapharsing 
Ability : Journal of Education and Social Analysis

Volume 2, Issue 4, Oktober 2021

Page : 102-109

- Translation

APM - Reading the Sentences

- Alternating between S1 to TL

- Paraphrasing

- Translation

AST - Reading sentences

- Alternating between SL to TL

- Consulting the dictionary

- Translation

- Monitoring proposed Translation

CWS - Reading the sentences

- Alternating between SL to TL

- Consulting the dictionary

- Paraphrasing

- Translation

DES - Reading the sentences

- Alternating between Sl to TL

- Translation

- Consulting the Dictionary

- Paraphrasing

- Monitoring proposed Translation

Cognitive process in translating is dealt with the cognitive science. The cognitive science works on the study of cognition involving the discipline $f$ psychology and linguistics. Translation process involves of two fields psychology of science and linguistics. The process meant here refers to the cognitive process occurring in the performance of translating.

Psychologically, cognitive process works on how human being processes of the information in his/her mind. Neisser (Hvelplund 2011:38) defines that cognitive process refers to all the process by which the sensory input is transformed, reduced, elaborated, stored, recovered, and used. He also adds that cognition refers to the ability of the mind to process information and to apply knowledge in an information processing setting.

In transforming the information from source language to target language, te process of translation occurs. Translation process is about human information processing in translating, it should be modeled in psychology domain of information processing, it takes places in both short-term and longterm memory by decoding text in the source language and encoding text into the target language through semantic representation, and it proceeds in a 
Ability : Journal of Education and Social Analysis

Volume 2, Issue 4, Oktober 2021

Page : 102-109

bottom-up and top down structure in processing text by means of analysis and synthesis phases (Bell, 1991:229). In other words, translation process is a cognitive process of information processing goes on with a translator's mind while translating. Translation is the result of the cognitive processing carried out by the translators.

To describe the mental activities, it is important to draw the distinction between behaviors and processes. Behaviors is an action or series of actions carried out by the translator, whether or not they lead to a result. It maybe a reading, re-reading, a dictionary search, silence and expletive uttered, or transcribing of notes on the original text. To analyze the cognitive process in translating, (1997:84) claims that is possible to describe the cognitive phenomena such as conceptualization built on linguistic statements coherently

It is based on the common observation which showed the translators' awareness of their cognitive steps while reading, writing, précis-writing and translating. This is particulary evident when they face problem which forces them to depart from routine operations.

Moreover, Dancette (1997:85) finds out that when the translators face with a difficulty, they can recall their questions, hypotheses and some of the steps of their reasoning. Therefore, they are able to talk about the process. However, processes are not visible, only clues to such process are visible. These processes are able to observe through the observation of the translators' behaviors. Behaviors are indication of a process which helps the observer to make reasonable hypotheses on what process is involved and validate intuitions about the nature of processes.

Dancette (1997:90) list out the types of behavior classified in the following :

1. Reading the text

This behavior describes the way in which the translator tackles the text. He or She firstly, read the whole source language text, or may read the text segment by segment as he or she proceeds with translation.

2. Alternating between source language and target language texts.

The translator alternates between the two texts, in general on the level of a term or part of a sentence, repeating the original term then the translator proposed equivalent. Sometimes an equivalent is automatically proposed and accepted, sometimes the alternating indicates hesitation or questioning.

3. Intralinguistic repetition

The translator repeats a term, a segment of a sentence, or expression in either the source text or the target text. Depending on the context of its appearance. This 
intralingual behavior may denote in decision or a nsearch for an equivalent.

4. Paraphrasing

The translator paraphrases a segment in either the source text or the target text. It may apply to a segment of a source text to clarify a concept or to a segment of target text to clarify a concept or reformulate a propose translation.

5. Translation

The translator proposes a translation orally or writes it down and expresses it orally.

6. Consulting the dictionary

In this type of behavior, it is noted only with which dictionary is used.

7. Monitoring proposed translation

There are two kinds of monitoring, namely (1) Lexical Monitoring in which the translator questions the adequacy of a term or an expression and (2) contextual monitoring in which the translator checks his or her interpretation or equivalence conforms to what he or she understands of the source language text, the domain of the text, or the reality in the outside world.

\section{Extralinguistic Comments}

There are three kinds of comments, namely (1) reflection showing identification of any problem, (2) extralinguistic reflection and search aimed at clarifying the context by relating extralinguistic information to the text segment being worked on, and (3) metalinguistic comment, judgments on the position of the author ideas expressed.

9. Linguistic Comment

Such comments include justification for translation choice, comments on the author's or on the translator's own stylistic choices for the translation, and comments on the language itself.

\section{CONCLUSION}

Based on the data analysis, it was found thatThere are six findings of the students' manners cognitive process in translating EPV into Indonesian. They are (1) reading the text, (2) alternating beyween SL and TL (3) monitoring the proposed translation (4) consulting the dictionary (5) paraphrasing (6)translation 
Ability : Journal of Education and Social Analysis

Volume 2, Issue 4, Oktober 2021

Page : 102-109

\section{REFERENCES}

Altenbergh, E. (2010). English Grammar Understanding Basic. New York: Cambridge University Press.

Bell, R. T. (1991). Translation and Translating: Theory and Practice.London: Longman.

Bogdan, R. C. and Sari,K.B. (1992). Qualitative Research for Education: An Introduction to Theory and Methods. Neidham Heighs: Allyn and Bacon.

Carl,W.H. (2000). The Ultimate Phrasal Verb Book, New York: Barron' s2000

Catford, J. C. (1965). A Linguistic Theory of Translation: An Essay in Applied Linguistics. London: Oxford University Press.

Cohen. (2007). Research Methods in Education. London: Routledge Taylor \& Francis.

Danks, (1997). Cognitive Processes in Translation and Interpreting. London: Sage. 